\title{
A Integração de Atividades Teóricas e Experimentais no Ensino de Física através de Ciclos de Modelagem: Um Estudo de Caso Exploratório no Ensino Superior
}

(Integrating Theoretical and Experimental Physics Teaching Activities through Modeling Cycles: An Exploratory Case Study in an Undergraduate Course)

\section{LEONARDO ALBUQUERQUE HEIDEMANN, IVES SOLANO ARAUJO $\mathrm{A}$ ELIANE ANGELA VEIT}

Universidade Federal do Rio Grande do Sul (leonardo@heidemann.com.br, ives@if.ufrgs.br, eav@if.ufrgs.br)

Resumo. Neste artigo apresentam-se resultados de um estudo exploratório em que foi avaliada a influência de atividades experimentais, envolvendo oscilações mecânicas, fluidos e termodinâmica, com enfoque na modelagem científica: i) na atitude de estudantes de graduação em Física em relação às aulas de laboratório; ii) na percepção deles sobre uma boa aula de laboratório; e iii) na capacidade deles para relacionar os modelos teóricos da Física, o processo de modelagem científica e a experimentação. Os resultados evidenciam que o enfoque no processo de modelagem científica gerou atitudes positivas dos estudantes em relação às aulas experimentais, especialmente em decorrência da liberdade que possuíam durante as atividades. No entanto, possivelmente devido à forma implícita como aspectos epistemológicos foram tratados, não foi observada evolução satisfatória na capacidade dos estudantes de relacionar suas investigações com o processo de modelagem científica, e foi bastante tímido o avanço em suas concepções sobre a natureza da Ciência.

Abstract. In this paper we present the results of an exploratory study in which it was evaluated the influence of experimental activities based on scientific modeling of mechanical oscillations, fluids and thermodynamics phenomena on: i) the attitudes of undergraduate physics majors toward laboratory class ii) their perceptions of a good laboratory class; and iii) their ability to relate the theoretical models of physics to the process of scientific modeling and experimentation. The results shown the focus on scientific modeling created positive attitudes on students toward laboratory classes, especially due to the freedom they had during the activities. However, satisfactory evolution of students' abilities to relate their investigations to the process of scientific modeling has not been observed, possibly due to the implicit way in which epistemological aspects were treated; the advancement of their conceptions regarding the nature of science was, in fact, rather timid.

Palavras-chave: modelagem científica, atividades experimentais, ciclos de modelagem

Keyword: scientific modeling, experimental activities, modeling cycles

\section{Introdução}

As disciplinas experimentais dos cursos de graduação em Física frequentemente são conduzidas por meio de atividades que levam os estudantes a seguir de forma mecânica roteiros excessivamente dirigidos com o objetivo de provar leis físicas. Essas atividades, além de colaborarem para que os estudantes tenham sentimentos desfavoráveis em relação às aulas experimentais, em função de elas serem monótonas e pouco proveitosas (HODSON, 1994; HOFSTEIN; LUNETTA, 2004; DAY, 2015), contribuem para que eles adotem concepções epistemológicas ingênuas, alinhadas com ideias empiristas-indutivistas (BORGES, 2002; TRUMPER, 2003; ABD-ELKHALICK, 2012). Preocupados com esse cenário, decidimos investigar o impacto de 
uma proposta de ensino delineada com o propósito de possibilitar uma postura mais ativa dos estudantes durante as tarefas experimentais e um avanço em suas concepções no sentido de torná-las mais alinhadas com concepções epistemológicas contemporâneas. Para isso, delineamos, com base na concepção de Mario Bunge (1974; 2010) sobre o processo de modelagem científica e na proposta de ciclos de modelagem de David Hestenes (2006), atividades experimentais em que procurávamos enfatizar o processo de modelagem científica. Partimos do pressuposto de que, por meio dessas atividades, os estudantes: i) seriam defrontados com problemas mais abertos, possibilitando um maior envolvimento deles com as atividades realizadas e, em decorrência disso, o desenvolvimento de atitudes mais positivas em relação às aulas experimentais, e ii) teriam contato com situações que evidenciam o caráter representacional dos modelos científicos, possibilitando o desenvolvimento de concepções de Ciência mais maduras.

Nossa opção por focar as atividades desenvolvidas no processo de modelagem científica foi amparada nas potencialidades desse enfoque identificadas em pesquisas da área de ensino de Ciências. Por exemplo, Louca e Zacharia (2012), em um artigo de revisão da literatura, destacam investigações que relacionam o enfoque na modelagem científica com melhores resultados dos estudantes em termos: i) da compreensão conceitual dos conteúdos científicos; ii) da compreensão da natureza operatória da Ciência; iii) da capacidade para empregarem habilidades procedimentais e de raciocínio na resolução de problemas; iv) do desenvolvimento do pensamento e da linguagem científica possibilitando o compartilhamento, a discussão e a crítica de suas ideias, promovendo a reflexão sobre as suas próprias aprendizagens. Os autores destacam ainda que, quando estabelecem claramente seus objetivos no início de suas investigações, os estudantes despendem mais tempo refletindo holisticamente sobre o modelo que construirão, culminando no uso de evidências precisas e convincentes para apoiar suas decisões de modelagem. Ainda que se possa identificar uma série de potencialidades relacionadas ao desenvolvimento cognitivo dos estudantes, Louca e Zacharia (idem) argumentam que mais investigações são necessárias, pois a maioria dos estudos que investiga aspectos cognitivos no ensino de Ciências se volta somente para os resultados, sendo poucos os que centram a atenção no processo envolvido na modelagem.

Como as atividades delineadas neste estudo acarretavam uma dinâmica pouco comum, já que os estudantes tinham maior liberdade para conduzir suas investigações do que o usual em aulas experimentais, optamos por realizar um estudo exploratório 
para evidenciar as principais vantagens e limitações da metodologia empregada, possibilitando ainda a familiarização do pesquisador com a condução das atividades planejadas. Com essa concepção em mente, o propósito central da investigação apresentada neste artigo foi, por meio de uma melhor compreensão da dinâmica de ensino implementada nas atividades, produzir questões e proposições teóricas para nortearem estudos posteriores. Procuramos responder às seguintes questões de pesquisa:

Como e por que atividades experimentais focadas no processo de modelagem científica influenciam:

- a atitude ${ }^{1}$ dos estudantes em relação às atividades experimentais?

- a percepção dos estudantes sobre como deve ser desenvolvida uma boa aula de laboratório?

- a capacidade dos alunos de relacionar os modelos teóricos da Física, o processo de modelagem científica e a experimentação?

Entendendo que a proposta de atividade implementada na investigação era ainda incipiente, optamos por não adotar explicitamente um referencial teórico de aprendizagem específico. Prevíamos que, com o desenvolvimento da investigação e nosso aprofundamento na metodologia de ensino sob avaliação, teríamos melhores condições de optar por um referencial teórico adequado e consistente em estudos futuros. Nas próximas seções, detalharemos as características do estudo realizado e os principais resultados obtidos. Resultados preliminares dessa investigação foram publicados em Heidemann et al. (2013). Mais detalhes do estudo exposto neste artigo podem ser encontrados em Heidemann (2015).

\section{Metodologia de ensino}

A metodologia de ensino utilizada nas atividades deste estudo foi inspirada nos ciclos de modelagem de Hestenes (HEIDEMANN et al., 2012b). Vastamente difundidos nos EUA (BREWE, 2008), esses ciclos são delineados partindo do pressuposto de que os estudantes aprendem de forma mais significativa a partir de atividades que os envolvam ativamente na construção e no uso de modelos e que os façam comunicar seus resultados aos colegas (HESTENES, 2006).

\footnotetext{
${ }^{1}$ Neste estudo, o termo "atitude" é entendido como uma disposição que reflete o sentimento de um indivíduo para responder favorável ou desfavoravelmente frente a um objeto, pessoa, instituição ou evento. Mais detalhes sobre o significado atribuído a essa expressão nesta pesquisa são apresentados em Heidemann et al. (2012a).
} 
Motivados pela proposta de Hestenes, as atividades conduzidas neste estudo foram desenvolvidas em três etapas. Na primeira delas, denominada discussão prélaboratorial, buscamos, por meio de um debate realizado entre o professor $^{2}$ e os estudantes, estabelecer um entendimento comum de uma pergunta sobre um sistema ou evento físico a ser respondida por meio da construção ou do uso de um modelo científico. Como não eram fornecidos roteiros aos estudantes, pois desejávamos que eles fossem envolvidos no delineamento, execução e análise de suas investigações experimentais, a apresentação do problema a ser investigado era realizada pelo professor por meio de uma exposição oral dialogada, conduzida com o intuito de assegurar que os estudantes compreendessem o propósito da atividade, que sempre era vinculado com o processo de modelagem científica.

$\mathrm{Na}$ segunda etapa das atividades, que é denominada investigação, os estudantes, em pequenos grupos, trabalharam no planejamento e na condução de experimentos para resolver o problema proposto. Admitindo que a habilidade de modelar dos estudantes, e assim compreender, depende das ferramentas de representação (equações, gráficos, tabelas, diagramas etc.) que eles dominam, o professor os auxiliava para que desenvolvessem habilidades para o uso dessas ferramentas quando elas eram necessárias nas suas investigações. Além disso, termos técnicos eram introduzidos pelo professor na medida em que eram necessários para aprimorar a qualidade do discurso dos estudantes.

$\mathrm{Na}$ última etapa das atividades, denominada discussão pós-laboratorial, os alunos, utilizando pequenos quadros-brancos $(100 \mathrm{~cm} \times 75 \mathrm{~cm})$, apresentavam as suas conclusões ao grande grupo (JACKSON et al., 2008). Para isso, utilizavam diferentes ferramentas de representação destacando-as em seus quadros-brancos, como é ilustrado na Figura 1. O objetivo primordial dessa etapa era possibilitar que os estudantes aprimorassem suas habilidades de argumentação na forma oral. $\mathrm{O}$ estabelecimento de um clima de abertura e respeito era muito importante para que os estudantes se sentissem incentivados a participar, explicitando suas ideias e raciocínios de modo que, a partir de suas contribuições, se estabelecessem as bases para o compartilhamento de significados entre os participantes do processo de ensino-aprendizagem. Ressalta-se que os quadros-brancos também foram utilizados pelos estudantes durante os compartilhamentos de ideias durante a etapa de investigação das atividades.

\footnotetext{
${ }^{2}$ Neste estudo, o primeiro autor deste trabalho, além do papel de pesquisador também exerceu o papel de ministrante da disciplina.
} 


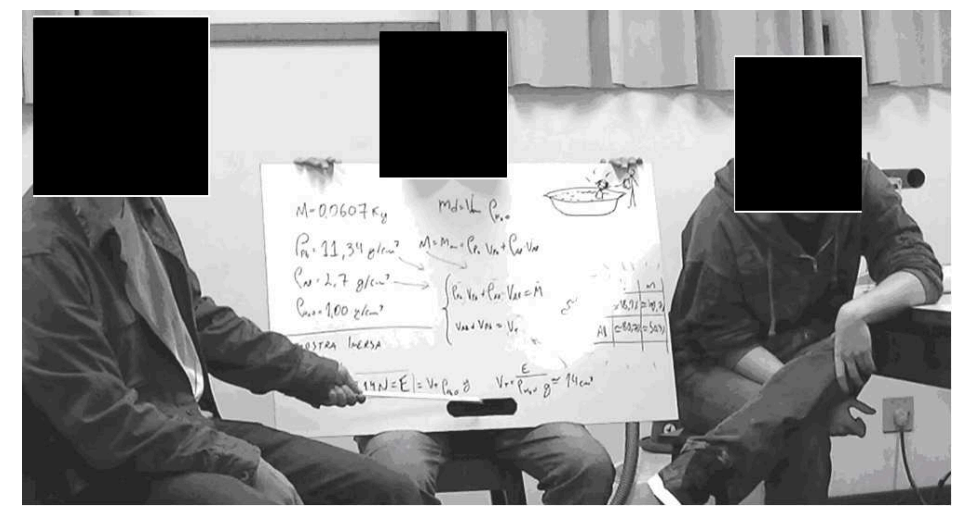

Figura 1 - Pequenos quadros-brancos foram utilizados pelos estudantes nas discussões finais, facilitando a comparação entre os dados obtidos por suas investigações ${ }^{3}$.

Fonte: Pesquisa

Cabe ressaltar que Hestenes propõe, além dos ciclos de modelagem, uma teoria de modelagem que abrange concepções sobre os processos de modelagem científica e modelagem mental. No entanto, entendemos que as concepções de Hestenes são expostas em seus artigos de modo muito superficial. Em relação à sua concepção epistemológica, por exemplo, o autor não esclarece com satisfatória profundidade como as suas considerações possibilitam compreender o processo de modelagem de eventos físicos que não pertençam ao campo da Mecânica, pois a quase totalidade dos exemplos tratados pelo autor em seus artigos envolvem a construção de representações de situações pertencentes a essa área do conhecimento.

Em decorrência das limitações identificadas na teoria de Hestenes, decidimos adotar neste estudo a concepção de Ciência de Bunge (1974; 2010), principalmente em função da sua clareza sobre o processo de modelagem científica e do seu potencial para amparar pesquisas com enfoque no ensino de Ciências já debatido em trabalhos anteriores (e.g., BRANDÃO et al., 2011; CUPANI; PIETROCOLA, 2002; PIETROCOLA, 1999; WESTPHAL; PINHEIRO, 2004). Especificamente, procuramos destacar nas atividades três aspectos centrais da concepção de modelagem de Bunge, explicados em detalhes por Pietrocola (1999) e por Brandão et al. (2011): i) a impossibilidade de se testar diretamente uma teoria geral (e.g., Leis de Newton) por meio de dados coletados experimentalmente, prescindindo do uso de um modelo teórico, pois as teorias gerais, ao contrário dos modelos teóricos (e.g., modelo newtoniano de pêndulo simples), não fornecem predições sobre eventos particulares da realidade; ii) o caráter representacional dos modelos teóricos, enfatizando que eles são

\footnotetext{
${ }^{3}$ Os estudantes assinaram um termo circunstanciado em que autorizam o uso das fotos e depoimentos colhidos na investigação em artigos científicos. Tal termo pode ser consultado em Heidemann (2015).
} 
representações esquemáticas recheadas de idealizações e aproximações, e nunca cópias especulares dos referentes e eventos que representam, tornando discrepâncias entre predições de modelos teóricos e resultados empíricos inevitáveis; e iii) que o domínio de validade dos modelos teóricos é extrapolado quando a influência dos aspectos desprezados torna essas discrepâncias inaceitáveis frente ao grau de precisão desejado. Com esses aspectos em mente, foram delineados quatro ciclos de modelagem, cujos enunciados são expostos no Quadro 1.

Com os ciclos de modelagem expostos no Quadro 1, pretendíamos que os estudantes desenvolvessem competências para enfrentarem situações que envolvem a confecção e o uso de modelos. Uma vez que o programa da disciplina em que seria feito o estudo exploratório não prevê a introdução de noções de epistemologia, julgamos não ser adequado introduzir debates explícitos sobre a natureza da Ciência, ainda que haja trabalhos na literatura que concluem que debates explícitos sobre epistemologia são necessários para que os estudantes evoluam em suas concepções sobre Ciências (e.g., LEDERMAN, 2006; PRINS et al., 2011).

Embora não tenhamos realizado debates explícitos sobre aspectos relacionados com a natureza dos modelos científicos, procurávamos defrontar os estudantes com situações que envolviam esses aspectos de forma implícita. No ciclo de modelagem denominado "Pêndulos", por exemplo, pretendíamos enfatizar que parte das diferenças que existem entre dados experimentais e os resultados preditos por meio do uso de modelos teóricos é decorrente das simplificações da realidade consideradas nesses modelos. Para isso, nossa expectativa era que os alunos conduzissem experimentos onde avaliariam a influência das características dos pêndulos, como, por exemplo, suas amplitudes de oscilação ou os comprimentos dos seus fios de sustentação, no período dos mesmos. As investigações dos estudantes seriam embasadas então por comparações entre: i) predições construídas com o uso do modelo newtoniano de pêndulo simples, em que são consideradas diversas simplificações da realidade; e ii) dados coletados experimentalmente que, como tal, são influenciados por fatores desprezados no modelo de pêndulo simples. $\mathrm{O}$ uso do computador por parte dos alunos foi estimulado tanto para auxiliar a aquisição de dados como para a condução de experimentos virtuais. Em especial, incentivamos o uso dos softwares Tracker ${ }^{4}$ e Modellus ${ }^{5}$. Mais detalhes sobre o ciclo de modelagem "Pêndulos" podem ser consultados em Heidemann et al. (2012b).

\footnotetext{
${ }^{4}$ Disponível em: http://www.cabrillo.edu/ dbrown/tracker/. Acesso em: 01/06/2015.

${ }^{5}$ Disponível em: http://modellus.co/. Acesso em: 01/06/2015.
} 
Os ciclos de modelagem expostos no Quadro 1 foram conduzidos com

estudantes de graduação em Física. Na próxima seção, apresentamos as características

principais do contexto em que esta investigação foi realizada.

Quadro 1 - Enunciados dos ciclos de modelagem desenvolvidos

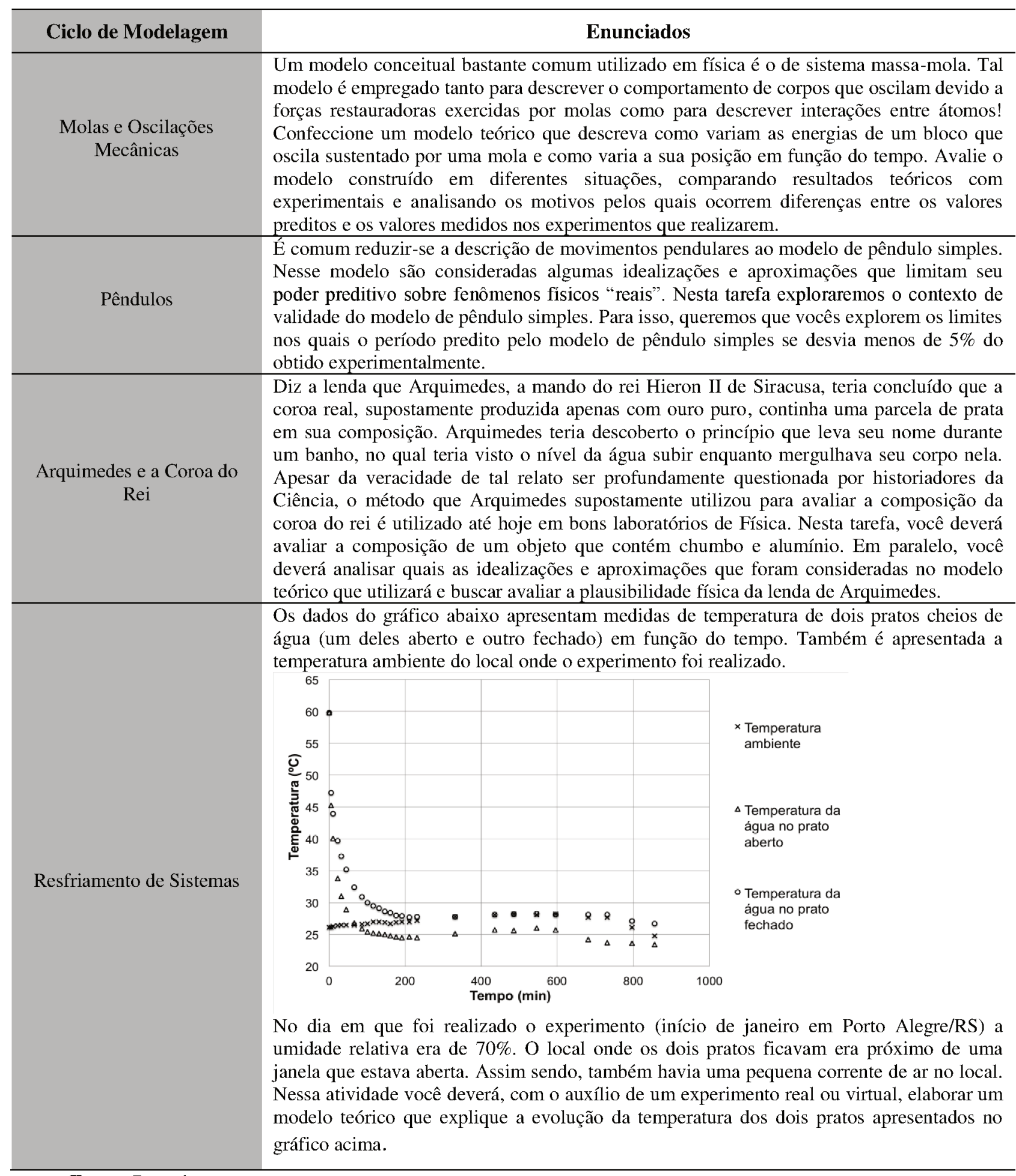

Fonte: Pesquisa 


\section{Contexto do estudo}

Os 14 estudantes de graduação em Física matriculados em uma turma de uma disciplina experimental que abordava conteúdos sobre oscilações mecânicas, fluidos e termodinâmica constituíram o caso investigado. Suas idades variavam entre 17 e 35 anos, tendo média de 22,5 anos e desvio padrão de 4,6 anos. Apenas três estudantes cursavam licenciatura; 11 estavam matriculados em ênfases do bacharelado (cinco em Astrofísica, quatro em Materiais e Nanotecnologia, um em Física Computacional, e um em Pesquisa Básica). No transcorrer da disciplina, dois estudantes evadiram da disciplina: um licenciando e um bacharelando com ênfase em Astrofísica. Com isso, a média de idade dos 12 participantes que terminaram a disciplina foi de 21,6 anos com desvio padrão de 3,1 anos.

Para condução deste estudo, 10 das 17 aulas tradicionalmente desenvolvidas na turma em que foi realizado o estudo foram substituídas por ciclos de modelagem, que foram conduzidos sem o uso de guias de atividades. As ações dos estudantes eram guiadas por orientações apresentadas pelo professor da disciplina de forma oral. Apenas quatro atividades se mantiveram com os roteiros tradicionais ${ }^{6}$. Duas aulas com demonstrações experimentais usualmente realizadas na disciplina (túnel de vento e motores térmicos) também foram mantidas. O Quadro 2 sintetiza o cronograma da turma experimental.

Quadro 2-Cronograma das aulas

\begin{tabular}{cc}
\hline Aulas & Atividades Realizadas \\
\hline 1 & Apresentação da disciplina e teste inicial \\
\hline 2,3 e 4 & Ciclo de Modelagem "Molas e Oscilações Mecânicas" \\
\hline 5 e 6 & Ciclo de Modelagem "Pêndulos" \\
\hline 7 & Atividade Experimental “A Constante da Gravitação Universal” \\
\hline 8 e 9 & Ciclo de Modelagem "Arquimedes e a Coroa do Rei” \\
\hline 10 & Demonstração sobre túnel de vento \\
\hline 11 & Atividade Experimental "Ondas Estacionárias" \\
\hline 12 & Atividade Experimental "Velocidade de Propagação do Som" \\
\hline 13 & Atividade Experimental "Dilatação Térmica Linear" \\
\hline 14,15 e 16 & Ciclo de Modelagem "Resfriamento de Sistemas" \\
\hline 17 & Teste final e demonstrações sobre máquinas térmicas \\
\hline
\end{tabular}

Fonte: Pesquisa

\footnotetext{
${ }^{6}$ Disponíveis em: http://www.if.ufrgs.br/gpef/modelagem/Fis_II_A_2012/. Acesso em: 01/06/2015.
} 
Para delinearmos os procedimentos investigativos do estudo, usamos como referencial metodológico a proposta de estudo de casos de Robert Yin (2005; 2011). Na próxima seção, apresentaremos as características principais da metodologia de pesquisa empregada.

\section{Metodologia de pesquisa}

Devido às características dos ciclos de modelagem, que demandavam dos estudantes, além da execução dos seus experimentos, o planejamento e a interpretação das suas investigações, sabíamos que as ações dos participantes seriam bastante complexas, o que tornaria inviável o uso de qualquer metodologia de pesquisa que demandasse a desconstrução das ações dos indivíduos em um conjunto de eventos isolados. Em função disso, optamos por usar neste estudo as orientações metodológicas de Yin $(2005 ; 2011)$. Para o autor, um estudo de caso é "uma investigação empírica de um fenômeno contemporâneo dentro de seu contexto da vida real, especialmente quando os limites do fenômeno e o contexto não estão claramente definidos" (YIN, 2005, p. 32).

Yin (idem) recomenda que seja feito um estudo do tipo exploratório quando o objetivo do pesquisador é levantar hipóteses e proposições norteadoras para estudos posteriores. Visto que era justamente esse o nosso objetivo, optamos por realizar um estudo exploratório. Tal decisão foi tomada em função de ser a primeira vez que empregávamos a metodologia de ciclos de modelagem em um contexto como o desta investigação.

Sobre a escolha do caso a ser estudado, Yin (idem) dá destaque aos fundamentos lógicos que justificam a escolha de cinco diferentes tipos: decisivos, raros, típicos, reveladores e longitudinais. A opção por casos decisivos é adequada quando teorias especificam um conjunto claro de proposições que são válidas em circunstâncias bem estabelecidas. Devem existir casos decisivos que satisfaçam essas condições para testar essas teorias, e esses casos têm potencial para serem investigados. Casos raros ou extremos são úteis quando eles apresentam singularidades que justificam a necessidade de documentá-los e investigá-los. Casos que representam um conjunto de casos, denominados casos representativos ou típicos, são candidatos a serem objetos de estudo de investigações em função de que os resultados obtidos com eles poderão elucidar as características de outros casos semelhantes. Os casos reveladores são aqueles que dão 
oportunidade para que o pesquisador observe e analise um evento de difícil acesso, justificando o seu potencial para serem investigados. Por fim, os casos que podem ser analisados por um pesquisador ao longo de um grande intervalo de tempo, denominados de casos longitudinais, têm potencial para serem investigados por revelarem possíveis mudanças que podem ocorrer com o tempo. Neste estudo, optamos por um caso típico, realizando o estudo em uma turma que julgamos que representava o conjunto de turmas que costuma cursar a disciplina experimental onde foi realizada a investigação.

Seguindo as orientações metodológicas de Yin (2011), as análises de dados qualitativos deste estudo foram realizadas em cinco fases: compilação, desagrupamento, reagrupamento, interpretação e conclusão. Na etapa de compilação, os dados coletados foram organizados em grupos que facilitaram a visão e compreensão, otimizando e facilitando o trabalho do investigador. $\mathrm{Na}$ fase de desagrupamento, os dados foram divididos em fragmentos menores que, durante a fase de reagrupamento, foram rearranjados em grupos de dados, ou seja, em categorias. $\mathrm{Na}$ etapa de interpretação, os materiais reagrupados foram interpretados, produzindo a narrativa analítica que amparou o pesquisador na elaboração das conclusões do estudo.

Ainda seguindo as recomendações de Yin (2005), para cada uma das questões de pesquisa do estudo, estabelecemos previamente os procedimentos que dirigiram a coleta de dados da investigação, assim como criamos instrumentos de coleta de dados que tivessem potencial para produzir respostas às questões norteadoras. Por exemplo, um dos instrumentos desenvolvidos e aplicados foi um questionário, respondido pelos estudantes no início e no final da disciplina, no qual era solicitado que os respondentes apontassem os seus níveis de concordância com uma série de afirmativas do tipo: "Gosto de aulas de laboratório de Física". A concordância (ou discordância) dos estudantes com essa afirmativa permitiria avaliar se eles tinham uma atitude positiva (ou negativa) em relação às atividades experimentais. Cabe ressaltar que, ainda que tenhamos partido de questões norteadoras, adotamos uma postura exploratória, mantendo-nos abertos para coletar evidências não planejadas.

Buscando utilizar múltiplas fontes de evidência, como sugere Yin (idem), usamos os seguintes instrumentos de coleta de dados:

a) um questionário aplicado como teste inicial e teste final no qual os estudantes manifestaram, entre outras coisas, suas experiências em disciplinas experimentais e suas expectativas para a disciplina conduzida no estudo. Além disso, eles apontaram seus níveis de concordância com uma série de afirmativas 
que tinham como intuito possibilitar inferências sobre as atitudes dos participantes em relação às aulas experimentais, as crenças dos estudantes sobre o que eles entendem por uma boa aula de laboratório, e as concepções dos alunos sobre a natureza da Ciência, dos modelos científicos e da modelagem. Essas últimas afirmativas foram reproduzidas do trabalho de Brandão et al. (2011). Detalhes sobre esse questionário podem ser consultados em Heidemann (2015);

b) filmagens das discussões finais dos ciclos de modelagem;

c) relatórios produzidos pelos alunos sobre cada uma das atividades experimentais realizadas; e

d) gravações de entrevistas semiestruturadas realizadas após o término da disciplina com quatro estudantes, escolhidos de modo a abarcar quatro diferentes perfis de participantes. Optamos então por entrevistar estudantes que manifestaram: preferência por aulas tradicionais (Estudante 6); frustação com o ensino tradicional (Estudante 12); grande entusiasmo com as atividades de modelagem (Estudante 11); competência na elaboração de relatórios experimentais de boa qualidade (Estudante 7).

Os principais trechos das manifestações dos alunos nos questionários, nas filmagens, nas entrevistas e nos relatórios foram transcritos, organizados em um banco de dados e analisados seguindo as orientações propostas por Yin para a análise de dados qualitativos. Na próxima seção apresentamos as conclusões construídas a partir dos dados coletados com os referidos instrumentos de coleta de dados.

\section{Resultados}

Buscando tornar clara a exposição, apresentamos os resultados da investigação em três subseções que abordam cada uma das questões que nortearam o estudo e, de imediato, passamos às evidências coletadas.

\section{Como atividades experimentais focadas no processo de modelagem científica influenciam a atitude dos estudantes em relação às atividades experimentais?}

Para medir a atitude dos estudantes em relação às aulas experimentais, foi solicitado que apresentassem seus níveis de concordância com oito afirmativas presentes no questionário respondido no início e no final da disciplina. Entre essas afirmativas estava, por exemplo, a seguinte: "Não me interesso pelas atividades 
desenvolvidas durante as aulas de laboratório de Física". Procurando validar o conjunto de afirmativas com um instrumento de medida da atitude dos respondentes em relação às atividades experimentais, utilizamo-las como teste inicial e final com todos os estudantes de duas disciplinas experimentais introdutórias de um curso de Física, totalizando 124 respostas. Esses respostas foram então convertidas em valores entre $1 \mathrm{e}$ 5, e as atitudes dos participantes foram mensuradas pelo somatório de suas respostas para cada uma das oito afirmativas presentes no questionário ${ }^{7}$. O coeficiente de fidedignidade alfa de Cronbach (FIELD, 2009) obtido para tal amostra com as oito afirmativas do questionário foi de 0,853 , o que pode ser entendido como uma evidência de que os níveis de concordância com as afirmativas referem-se a um mesmo construto e de que elas possuem validade interna.

Normalizamos as atitudes em relação às aulas experimentais dos participantes dessa investigação para valores entre 0 e 10 . No teste inicial, a atitude média dos alunos foi de 6,5 com desvio padrão de 1,2. No teste final, a média das atitudes foi de 7,0 com desvio padrão de 1,3. Devido ao reduzido número de participantes no estudo, para avaliar se as diferenças de suas atitudes em relação às aulas experimentais antes e depois da disciplina são estatisticamente significativas, optamos por um teste nãoparamétrico: o teste de Wilcoxon pareado. Tal teste é adequado para situações em que se deseja comparar amostras dependentes (para mais detalhes, consulte HEIDEMANN, 2015). O resultado da aplicação do teste aos dados coletados apontou que tais diferenças não são estatisticamente significativas ao nível de $5 \%$.

Com o intuito de aprofundar a análise sobre as atitudes dos estudantes frente às atividades experimentais, realizamos também uma análise qualitativa das manifestações expostas pelos participantes no questionário usado como teste final. Essa análise forneceu evidências de que os estudantes tinham uma atitude positiva em relação aos ciclos de modelagem ao final da disciplina. Quando eram convidados a explicitar se suas expectativas com a disciplina foram alcançadas no teste final, todos os doze estudantes manifestaram que saíram satisfeitos com as atividades conduzidas na disciplina. Pode-se agrupar as respostas dos estudantes em três categorias. Na primeira

\footnotetext{
${ }^{7}$ Nas análises quantitativas das respostas dos estudantes às questões em que apontavam seus níveis de concordância com afirmativas propostas, convertemos as respostas "discordo fortemente", "discordo", "indeciso ou sem opinião", "concordo" e "concordo fortemente" nos valores 1, 2, 3, 4 e 5, respectivamente, inserindo o sinal negativo no caso em que a concordância evidenciava um sentimento desfavorável. Por meio dessa conversão, as atitudes dos estudantes no início e no final do estudo foram mensuradas pelo somatório dos índices inferidos dos níveis de concordância dos estudantes com oito afirmativas do questionário.
} 
delas, que continha as respostas de seis estudantes, juntamos as manifestações daqueles que disseram que suas expectativas foram alcançadas. Um exemplo de resposta desta categoria é a apresentada pelo Estudante 3: "Sim [suas expectativas foram alcançadas na disciplina]. Aprendi muito na prática os fundamentos da Física". Na segunda categoria, que contém respostas de cinco estudantes, espontaneamente, os participantes afirmaram que suas expectativas foram superadas positivamente. A resposta do Estudante 11 exemplifica um enunciado dessa categoria: "[minhas expectativas] foram superadas, pois não imaginava que teria o ciclo de modelagem, que foi uma surpresa muito agradável". A terceira categoria englobou apenas a resposta do Estudante 8, que disse que suas expectativas não foram alcançadas, pois, no início da disciplina, ele esperava que a metodologia de ensino empregada seria semelhante à utilizada em uma disciplina experimental cursada em um semestre anterior, e tal expectativa não se concretizou. Ele disse:

Realmente achei que a aula de experimental seria tão ruim quanto a experimental I [referindo-se à disciplina cursada pelos estudantes no semestre anterior ao estudo]. Todavia, os ciclos de modelagem me deram uma liberdade de escolha de atuação do experimento que eu realmente me senti um físico de verdade.

Pode-se interpretar dessas categorias de respostas que todos os estudantes apresentaram um sentimento positivo frente aos ciclos de modelagem desenvolvidos na disciplina.

A manifestação do Estudante 8, além de evidenciar que ele possui uma atitude positiva em relação aos ciclos de modelagem, demonstra também que os problemas enfrentados nessas atividades lhe agradaram. Quando destaca no teste final a "liberdade de escolha de atuação do experimento", o estudante mostra que o caráter aberto das atividades propostas foi um fator que influenciou na formação da sua atitude em relação às aulas de laboratório. Em entrevista, o Estudante 12 fez uma manifestação semelhante. Ele disse: "Tem que dar liberdade. Claro que essa liberdade tem que ser guiada, mas eu acho deve ser assim". A concepção de que as atividades abertas são melhores que atividades dirigidas parece ter sido compartilhada por todos os estudantes, pois todos concordaram com a seguinte afirmativa no final da disciplina: "uma boa aula de laboratório deve dar liberdade para que os alunos decidam a forma como resolverão os problemas propostos nas atividades". Outros dados que demonstram que os estudantes gostaram de enfrentar problemas abertos são suas manifestações no teste final quando 
solicitado que apontassem as vantagens e as desvantagens das aulas com enfoque na modelagem científica e das aulas tradicionais.

A categorização das respostas dos estudantes, que será mais profundamente debatida na próxima seção, evidenciou que seis deles destacaram a liberdade para construir e utilizar seus próprios modelos como uma vantagem dos ciclos de modelagem, assim como três participantes apontaram a falta de liberdade dada aos estudantes como uma desvantagem das aulas tradicionais. Esses resultados nos dão evidência de que o enfrentamento de autênticas investigações, em que os estudantes têm liberdade para tomar decisões, tem potencial para promover um maior envolvimento deles com as atividades.

Quando questionados no teste final sobre as suas preferências em termos dos métodos de ensino utilizados na disciplina, 11 alunos apontaram preferir as atividades de modelagem, e apenas dois preferiram as atividades tradicionais. Em entrevista, um desses dois estudantes, o Estudante 6, justificou sua escolha destacando que o tempo dispendido para a confecção do delineamento dos experimentos realizados nos ciclos de modelagem era longo: "ficava menos tempo focado na parte experimental, que talvez. fosse o objetivo da aula experimental". Contudo, esse mesmo aluno disse que gostou das discussões finais: "Bah... Essa era a parte que eu mais gostava. Eu sou mais tímido, então eu não falava tanto, mas... de discutir ali no final... bah... eu acho isso bom [...] ter que discutir todos os resultados com todo mundo". Essa manifestação do Estudante 6 parece representar a opinião dos quatro entrevistados no estudo. A análise qualitativa dessas entrevistas resultou em uma única categoria, pois os quatro afirmaram ter gostado muito das discussões finais. Um exemplo de declaração dessa categoria é a apresentada pelo Estudante 11:

É o que mais eu gostava. Acho que a essência é isso. É troca de ideia, é um questionar o trabalho do outro. [pausa] Às vezes até as pessoas ficam até meio assim 'ah... não vou ferrar o trabalho dele, senão ele vai ferrar o meu', mas não é bem assim. [...] Com o tempo foi melhorando.

As discussões finais, portanto, foram possivelmente o aspecto que mais agradou os estudantes nos ciclos de modelagem.

Destacamos que, para o sucesso das discussões finais, a promoção de um ambiente dialógico foi fundamental. Na primeira vez em que a discussão final ocorreu, os estudantes pouco interagiram, realizando apresentações burocráticas e rápidas. Com o desenvolvimento da disciplina, eles passaram a compreender a proposta e a se envolver mais nas discussões. O Estudante 6 destacou essa evolução em sua entrevista. 
Ele atribuiu as dificuldades enfrentadas nas primeiras discussões finais à impressão que os estudantes tinham de que estavam sendo avaliados, dizendo:

Eu acho que era mais por encarar aquilo como avaliação. [...] É diferente se expor sendo avaliado e se expor sem ser avaliado. [...] Com o passar do tempo, eles passaram a encarar aquilo mais naturalmente. Não é esse bicho papão todo fazer uma apresentação.

Visto que as falas dos estudantes nos forneciam algumas evidências de que a atitude deles em relação às aulas de laboratório era mais positiva após a disciplina, buscamos avaliar o motivo pelo qual o questionário utilizado no estudo não detectou tal evolução. Após uma conversa informal com o Estudante 4, e a reanálise de suas respostas, levantamos uma hipótese. Em suas manifestações no teste final, esse estudante evidenciou uma atitude frente aos ciclos de modelagem bem mais positiva do que em relação às aulas experimentais tradicionais. Ele disse:

Após a experimental I [disciplina que antecede a disciplina do contexto do estudo] havia ficado realmente desanimado (sem expectativas). O método utilizado dessa vez foi de longe mais eficaz e mesmo eu não sendo fã de física experimental, aproveitei a cadeira.

No entanto, suas atitudes em relação às aulas de laboratório foram mensuradas como 4,3 no teste inicial e como 4,0 no teste final, o que representa uma tímida mudança na atitude do estudante no sentido de se tornar menos positiva, o que era inconsistente com o seu discurso. Estabelecemos então a seguinte hipótese alternativa: as respostas dos estudantes às questões do teste final utilizadas para medir suas atitudes em relação às atividades experimentais não refletiam os seus sentimentos sobre os ciclos de modelagem. Ainda que não tenhamos dados suficientes para avaliar tal hipótese de forma mais profunda, colhemos uma evidência que lhe dá apoio empírico. Quando questionado sobre ter demonstrado um sentimento negativo em relação às aulas de laboratório nas suas respostas ao teste final, o que parecia inconsistente com o seu discurso, que evidenciava uma atitude muito positiva em relação às atividades com enfoque na modelagem científica, o Estudante 4 argumentou que respondeu às questões tendo em mente as aulas de laboratório tradicionais. Por exemplo, no teste final, quando questionado sobre a afirmativa "Sinto vontade de ir para as aulas de laboratório de Física", o Estudante 4 assinalou seu nível de concordância com ela considerando as aulas de laboratório em que não foram realizados ciclos de modelagem, e não as aulas norteadas por essa metodologia. É possível que mais alunos tenham respondido ao questionário usando o mesmo raciocínio, o que pode ser uma evidência de que a redação das afirmativas propostas no teste final precisa ser mais específica nos 
próximos estudos, sendo substituída, por exemplo, a expressão "aulas de laboratório de Física" por "aulas experimentais com enfoque na modelagem científica".

Em síntese, podemos concluir que as atividades de modelagem promoveram uma atitude positiva dos alunos em relação às aulas experimentais. Pode-se concluir ainda que, apesar de a aplicação do questionário utilizado para medir as atitudes dos estudantes frente às aulas de laboratório tenha demonstrado que ele tem validade interna, foram coletadas evidências de que o construto efetivamente medido com ele não é a atitude dos estudantes em relação aos ciclos de modelagem, mas sim em relação às aulas de laboratório tradicionais. Por fim, foram coletados dados que evidenciam que as atitudes dos estudantes, bastante positivas em relação aos ciclos de modelagem, foram influenciadas pela liberdade que eles possuíam durante as atividades em que eles eram defrontados com autênticas investigações.

\section{Como e por que atividades experimentais focadas no processo de modelagem científica influenciam na percepção dos estudantes sobre como deve ser desenvolvida uma boa aula de laboratório?}

Inicialmente, realizamos a categorização das respostas dos estudantes às questões dissertativas do teste inicial, o que evidenciou que eles entendem que a principal função das aulas de laboratório de Física é de complementar os conhecimentos debatidos nas aulas teóricas. Foram identificadas manifestações de oito alunos que enfatizam tal aspecto de algum modo nas suas respostas. O Estudante 2, por exemplo, afirmou que a sua expectativa para a disciplina é de "aprender os casos reais e aplicados do conteúdo trabalhado em Física II [disciplina de Física Geral em que são abordados os conteúdos de oscilações mecânicas, fluidos e termodinâmica]". Outro fator que corrobora tal conclusão é que todos os estudantes apontaram que concordam, no teste final, com a afirmativa que diz que "uma boa aula de laboratório deve ilustrar na prática as leis e teorias apresentadas nas aulas teóricas de Física". Conclusões semelhantes podem ser inferidas da análise das respostas dos estudantes no teste final à seguinte afirmativa: "uma boa aula de laboratório deve ilustrar experimentalmente os problemas acadêmicos resolvidos nas aulas teóricas de Física".

Dos 14 respondentes, 13 concordaram com as afirmativas do teste inicial que ressaltavam a necessidade de se destacar a aplicabilidade dos conteúdos de Física nas aulas de laboratório. Apenas um estudante se mostrou indeciso em relação a elas. Por outro lado, o número de alunos que concorda com as afirmativas que ressaltam que as 
aulas de laboratório devem ser focadas em aspectos que serão importantes na carreira profissional dos alunos e em problemas do cotidiano dos estudantes cai para apenas sete respondentes. Tais dados mostram que, apesar de os participantes do estudo defenderem que as aulas de laboratório necessitam envolver aplicações dos conteúdos de Física, eles não apresentam uma visão utilitarista da disciplina, ou seja, não entendem que o conhecimento debatido nas aulas necessariamente tenha de ter uma utilidade evidente e imediata.

O desenvolvimento de habilidades experimentais também é considerado um aspecto importante das aulas de laboratório pelos estudantes. Todos eles concordaram com a afirmativa do teste inicial que defendia que as aulas de laboratório devem promover habilidades relacionadas com análises estatísticas de dados experimentais. Somente dois respondentes não concordaram com a afirmativa que destaca a necessidade de se promover habilidades de manuseio dos instrumentos experimentais nas aulas de laboratório.

Uma comparação entre os níveis de concordância dos participantes com as afirmativas propostas nos testes inicial e final nos permite concluir que a visão dos alunos sobre como deve ser uma boa aula de laboratório pouco mudou ao final do nosso estudo. No entanto, pode-se detectar uma mudança que possivelmente esteja relacionada com a evolução que detectamos na concepção dos estudantes quanto à natureza dos modelos científicos.

Em função de os estudantes tratarem com mais naturalidade as diferenças entre os valores preditos pelos modelos teóricos e os dados coletados experimentalmente, eles passaram a reconhecer que, por mais precisos que sejam os instrumentos de medida, resultados teóricos e experimentais não serão exatamente iguais a não ser por acaso. Em decorrência disso, eles passaram a ter menos apreço por instrumentos precisos e a aceitarem com mais tranquilidade as incertezas experimentais. Assim, entendendo que as diferenças entre as predições dos modelos teóricos e os dados coletados empiricamente são inevitáveis, os estudantes passaram a compreender que a análise dessas discrepâncias não possibilita a refutação de uma teoria. Tal fato é evidente nos níveis de concordância apontados pelos participantes às afirmativas expostas no Quadro 3, nas quais foram detectadas diferenças estatisticamente significativas entre as respostas dos participantes no teste inicial e no final. 
Quadro 3 - Afirmativas sobre boas aulas de laboratório nas quais houve diferenças estatisticamente significativas ao nível de $2 \%$ entre as respostas do teste inicial e do final. Os critérios utilizados para a conversão dos níveis de concordância são expostos na nota de rodapé 6. As significâncias estatísticas são dadas pelo teste de Wilcoxon pareado.

\begin{tabular}{clccc}
\hline & Uma boa aula de laboratório deve... & $\begin{array}{c}\text { Média } \\
\text { Teste } \\
\text { inicial }\end{array}$ & $\begin{array}{c}\text { Média } \\
\text { Teste } \\
\text { final }\end{array}$ & Sig. \\
\hline $\mathbf{1}$ & Envolver o uso de equipamentos bastante precisos e elaborados. & 4,0 & 3,1 & 0,008 \\
\hline $\mathbf{2}$ & $\begin{array}{l}\text { Ser planejada com o intuito de que os alunos não cometam erros e, } \\
\text { assim, obtenham resultados diferentes dos preditos pelos modelos } \\
\text { teóricos da Física. }\end{array}$ & 3,1 & \multirow{2}{*}{1,8} & 0,010 \\
\hline $\mathbf{3}$ & $\begin{array}{l}\text { Provar a eficiência das leis e teorias físicas para descrever } \\
\text { fenômenos físicos. }\end{array}$ & 4,1 & 3,5 & 0,014 \\
\hline
\end{tabular}

Fonte: Pesquisa

O grande número de estudantes que concordou com a afirmativa que dizia que "uma boa aula de laboratório deve dar liberdade para que os alunos decidam a forma como resolverão os problemas propostos nas atividades" mostra que os estudantes valorizam a liberdade nas aulas de laboratório. Apenas dois alunos não concordaram com tal frase no teste inicial, declarando-se indecisos. Já no teste final, todos os participantes passaram a concordar com essa afirmativa. Tal fato se refletiu na análise das respostas ao teste final, quando era solicitado que apontassem vantagens e desvantagens das aulas com enfoque na modelagem científica e das aulas tradicionais. Como já mencionamos na subseção anterior, a categorização das respostas dos estudantes evidenciou que seis destacaram a liberdade para construir e utilizar seus próprios modelos como uma vantagem dos ciclos de modelagem, assim como três participantes apontaram a falta de liberdade dada aos estudantes como uma desvantagem das aulas tradicionais. O Quadro 4 resume os principais aspectos destacados pelos estudantes no teste final. 
Quadro 4 - Categorização das vantagens e desvantagens das aulas com ciclos de modelagem e das aulas tradicionais destacadas pelos 12 participantes. Os valores entre parênteses indicam o número de respondentes que destacou cada vantagem ou desvantagem.

\begin{tabular}{|c|c|c|c|}
\hline \multicolumn{2}{|c|}{$\begin{array}{c}\text { Aulas com enfoque no processo } \\
\text { de modelagem científica }\end{array}$} & \multicolumn{2}{|c|}{ Aulas tradicionais } \\
\hline Vantagens & Desvantagens & Vantagens & Desvantagens \\
\hline $\begin{array}{l}\text { Dão liberdade para } \\
\text { construir e utilizar meus } \\
\text { próprios modelos (6) }\end{array}$ & Exigem muito tempo (3) & $\begin{array}{c}\text { Aulas objetivas, com } \\
\text { experimentos concebidos } \\
\text { para o ensino de Física (4) }\end{array}$ & $\begin{array}{l}\text { As aulas são menos } \\
\text { interessantes (4) }\end{array}$ \\
\hline $\begin{array}{l}\text { Estimula o pensamento } \\
\text { científico, a criatividade e } \\
\text { a intuição física (5) }\end{array}$ & $\begin{array}{c}\text { Os relatórios } \\
\text { experimentais ficam muito } \\
\text { longos e trabalhosos (2) }\end{array}$ & $\begin{array}{l}\text { Os experimentos são mais } \\
\text { fáceis (3) }\end{array}$ & $\begin{array}{c}\text { Aprende-se menos que } \\
\text { com as aulas com enfoque } \\
\text { na modelagem científica } \\
\text { (4) }\end{array}$ \\
\hline $\begin{array}{l}\text { Aprende-se com as } \\
\text { discussões pós- } \\
\text { laboratoriais (4) }\end{array}$ & $\begin{array}{l}\text { A liberdade dada pode } \\
\text { promover falta de } \\
\text { responsabilidade nos } \\
\text { alunos (2) }\end{array}$ & $\begin{array}{l}\text { Os experimentos são mais } \\
\text { rápidos (2) }\end{array}$ & $\begin{array}{l}\text { Não dão liberdade ao } \\
\text { aluno (3) }\end{array}$ \\
\hline $\begin{array}{l}\text { Os experimentos são } \\
\text { investigados com mais } \\
\text { profundidade }(2)\end{array}$ & & & $\begin{array}{c}\text { Não incentiva o } \\
\text { pensamento científico (3) }\end{array}$ \\
\hline
\end{tabular}

Fonte: Pesquisa

A análise do Quadro 4 evidencia que a distribuição adequada do tempo para a realização de cada atividade é um fator importante para os estudantes. A exigência de um longo intervalo de tempo foi tratada por eles como uma desvantagem das atividades enfocadas no processo de modelagem científica, assim como a rapidez com que os experimentos são desenvolvidos foi tratada como uma vantagem das aulas tradicionais. Tal resultado é consistente com as conclusões do trabalho de Deacon e Hajek (2011).

Em síntese, podemos concluir que, majoritariamente, os estudantes investigados, graduandos de Física, entendem que as aulas de laboratório devem complementar as aulas teóricas. Destaca-se ainda que eles não esperam que tais aulas tenham um perfil "utilitarista", ou seja, que elas tenham enfoque em aspectos que tenham utilidade imediata para as suas carreiras profissionais ou para suas vidas pessoais. A principal mudança promovida pela disciplina se refere à necessidade que os estudantes sentiam: i) de coletarem dados muito precisos nas aulas experimentais, que eles, ao final da disciplina, passaram a julgar como um dos aspectos não tão importante, e ii) de serem dirigidos durante os experimentos para que os dados coletados experimentalmente não tenham diferenças em relação às predições dos modelos teóricos, pois essas diferenças passaram a ser melhor compreendidas pelos participantes ao final da disciplina. Cabe ressaltar que, indo de encontro aos resultados de Deacon e Hajek (2011), que concluem 
que atividades abertas favorecem atitudes negativas dos estudantes em relação às atividades experimentais, o uso de problemas abertos foi, na visão dos estudantes, um aspecto positivo dos ciclos de modelagem.

Como e por que atividades experimentais focadas no processo de modelagem científica influenciam a capacidade dos alunos de relacionar os modelos teóricos da Física, o processo de modelagem científica e a experimentação?

Analisando os relatórios confeccionados pelos estudantes, constatamos que os objetivos experimentais apresentados pareciam demonstrar que eles evoluíram no sentido de superar concepções empiristas-indutivistas ingênuas. Demonstrando compreender que, na sua investigação, seu objetivo era construir um modelo para descrever um evento real, e não provar uma lei ou teoria, o Estudante 7, por exemplo, relatou o seguinte objetivo experimental para a atividade do primeiro ciclo de modelagem: [...] este trabalho destina-se a estudar o sistema massa-mola, comparando os dados teóricos com os observados em relação à energia e à posição do sistema, determinando um modelo para descrevê-lo.

Pôde-se identificar indícios não conclusivos sobre o uso de objetivos experimentais empiristas para justificar os experimentos, argumentando que as atividades tinham o intuito de provar ou refutar uma teoria, em apenas 8 dos 25 relatórios confeccionados. No relatório do Estudante 7 sobre o primeiro ciclo de modelagem, por exemplo, ele argumenta que o objetivo da sua investigação era "determinar a constante elástica da mola utilizada no experimento (através da lei de Hooke) e comprovar a dependência do período de oscilação com a massa do sistema". O uso do termo "comprovar" por parte do estudante pode ser um indício de que ele crê possível atribuir o caráter de verdade definitiva para as teorias científicas.

Dentre as características do processo de modelagem científica, a mais evidente no discurso dos estudantes foi o papel das idealizações para o desenvolvimento dos modelos científicos, que foram destacadas em 19 dos relatórios dos alunos. Como decorrência, pôde-se perceber que os estudantes passaram a tratar as discrepâncias entre as predições teóricas e os resultados experimentais com mais naturalidade. Um dos alunos, que no teste inicial se mostrava frustrado com essas discrepâncias, ressaltou tal fato: "A teoria... Enfim, ela tem um domínio de validade. [...] Tu vai até certo ponto com uma teoria". Pôde-se concluir ainda, por meio da análise dos relatórios dos estudantes, que as atividades voltadas à análise do domínio de validade de um modelo 
são mais propensas a enfocar o seu caráter representacional, evidenciando suas idealizações e aproximações.

Os níveis de concordância apontados pelos estudantes às afirmativas propostas no teste final nos evidenciou alguns avanços de suas concepções sobre a natureza dos modelos científicos. Para analisá-los, atribuímos os índices 1, 2, 3, 4 e 5 conforme critério exposto na nota de rodapé $6^{8}$. No entanto, usando o teste de Wilcoxon pareado (FIELD, 2009), foram detectadas diferenças estatisticamente significativas ao nível de $6 \%$ entre as respostas dos participantes no teste inicial e no final apenas em quatro das afirmativas, apresentadas no Quadro 5. É importante ressaltar que a diminuição das médias dos níveis de concordância dos participantes com as afirmativas 1,3 e 4 demonstra que eles passaram a discordar delas no teste final, o que pode ser entendido como uma evidência de uma evolução em suas concepções sobre Ciência. Outra evidência dessa evolução é o aumento das médias das concordâncias com a afirmativa 2.

As respostas dos estudantes às afirmativas apresentadas no Quadro 5 evidenciam que eles passaram a compreender que os modelos científicos não possibilitam o estabelecimento de predições perfeitamente precisas sobre um evento real, ou seja, que é natural que existam diferenças entre predições construídas por meio de modelos científicos e dados coletados empiricamente. Por exemplo, eles passaram a discordar mais no teste final do que no teste inicial da afirmativa 45. Desse modo, pode-se inferir que as atividades focadas na modelagem científica possibilitaram que os estudantes passassem a tratar as diferenças entre as predições dos modelos teóricos e os resultados experimentais com mais naturalidade. Isso possivelmente contribuiu para que eles construíssem atitudes mais positivas frente às atividades experimentais, pois a não compreensão dos fatores que originam as diferenças entre as predições e os dados empíricos em experimentos científicos pode ser um fator de frustração, como é evidenciado na manifestação do Aluno 12 no teste inicial: “O que observei é que muitos experimentos não fecham com a teoria, e isso é frustrante. Espero dessa disciplina que teoria e prática concordem mais".

\footnotetext{
${ }^{8}$ Não realizamos o agrupamento de afirmativas sugerido por Brandão et al. (2011), pois tal análise se mostrou inviável pelos valores insatisfatórios de coeficientes de fidedignidade encontrados (menores que $0,6)$.
} 
Quadro 5 - Afirmativas sobre a natureza dos modelos e da modelagem científica nas quais houve diferenças estatisticamente significativas ao nível de $6 \%$ entre as respostas nos testes inicial e final. Os critérios utilizados para a conversão dos níveis de concordância são expostos na nota de rodapé 6 . As significâncias estatísticas são dadas pelo teste de Wilcoxon pareado.

\begin{tabular}{clccc}
\hline \multicolumn{1}{c}{ Afirmativa } & $\begin{array}{c}\text { Média } \\
\text { Teste } \\
\text { inicial }\end{array}$ & $\begin{array}{c}\text { Média } \\
\text { Teste } \\
\text { final }\end{array}$ & Sig. \\
\hline $\mathbf{1}$ & $\begin{array}{l}\text { Só se pode afirmar que o conhecimento científico é definitivo } \\
\text { quando há concordância entre os resultados experimentais e suas } \\
\text { previsões em variadas condições. }\end{array}$ & 3,4 & 2,6 & 0,05 \\
\hline $\mathbf{2}$ & $\begin{array}{l}\text { Modelos científicos são construções humanas: sempre se originam } \\
\text { na mente de quem os (re)constrói. }\end{array}$ & 4,1 & 4,5 & 0,05 \\
\hline $\mathbf{3}$ & $\begin{array}{l}\text { Modelos científicos devem ser modificados sempre que não } \\
\text { estiverem de acordo com os dados empíricos ou com o corpo de } \\
\text { conhecimento já estabelecido. }\end{array}$ & 4,1 & 2,8 & 0,006 \\
\hline $\mathbf{4}$ & $\begin{array}{l}\text { Modelos científicos devem fornecer descrições exatas de sistemas } \\
\text { físicos. }\end{array}$ & 3,2 & 2,3 & 0,006 \\
\hline
\end{tabular}

Fonte: Pesquisa

Por outro lado, os níveis de concordância apontados pelos participantes às outras afirmativas propostas no teste final nos permitem concluir que as concepções de Ciência dos estudantes investigados estavam pouco alinhadas com as concepções epistemológicas contemporâneas e elas pouco se modificaram com as atividades desenvolvidas no estudo. Por exemplo, no teste final, dez dos 12 estudantes manifestaram uma postura alinhada ao senso comum, que tipicamente contém traços de ideias empiristas-indutivistas, concordando com a afirmativa que diz: "As leis científicas são generalizações de muitas observações e/ou experimentos". Também a concordância dos alunos com as duas seguintes afirmativas "o ponto de partida para a construção do conhecimento científico sempre deve ser a observação e a experimentação" e “a observação científica sempre é realizada a partir de algum pressuposto teórico sobre o objeto de estudo" evidenciam que eles não compreenderam o papel das teorias gerais no processo de construção de modelos teóricos.

Por meio das manifestações dos estudantes nas quatro entrevistas realizadas, pudemos identificar indícios de que eles permaneceram com concepções confusas sobre a natureza da Ciência e da modelagem científica após a disciplina. Em três delas pôdese identificar claros traços empiristas-indutivistas. Quando questionado sobre o papel dos experimentos no desenvolvimento da Física, o Estudante 12, por exemplo, respondeu: "Eu acho que o experimento é onde começa a surgir toda a Física". Logo em seguida, refletindo sobre as experiências da disciplina, nas quais os modelos 
dirigiam o delineamento dos experimentos, o aluno percebeu seu equívoco: "Nunca tinha pensado assim. O meu caminho era um só: que a realidade constrói a teoria". O Estudante 6, aparentando possuir uma concepção de Ciência mais contemporânea que os outros três entrevistados, atribuiu aos experimentos da Física o papel de possibilitar o teste de hipóteses e o delineamento de novas tecnologias.

Em relação às ideias dos alunos sobre modelos, as entrevistas realizadas após a disciplina evidenciaram que eles estavam pouco seguros de suas concepções. O Estudante 12, por exemplo, disse: "Um modelo pode ter como base uma teoria, mas pode ter como base um... [pausa] Eu estou falando o que me vem vindo na cabeça. Não são coisas consagradas para mim. Um modelo basicamente dá uma descrição matemática do que está havendo ali". A categorização das manifestações dos quatro estudantes entrevistados nos permitiu inferir que, além do Estudante 12, os estudantes 6 e 11 também entendem que modelos são estruturas matemáticas. O Estudante 6, por exemplo, afirmou: "Um modelo... [pausa] eu diria que é mais uma parte ferramental dessa teoria, né? Talvez a parte mais matemática ou, se não for matemática, a ferramenta mais computacional'. Apenas um dos entrevistados, o Estudante 7, destacou o caráter representacional dos modelos.

As manifestações dos quatro entrevistados que evidenciavam suas concepções sobre o termo "teoria" foram agrupadas em apenas uma categoria, pois todos eles compartilhavam a mesma concepção, entendendo que uma teoria é uma explicação para um fato específico. O Estudante 6, por exemplo, disse: "Teoria é mais uma explicação para algum fato, uma observação". O Estudante 12 afirmou que "uma teoria procura explicar a natureza de um fenômeno; o que está acontecendo".

Pôde-se perceber que o domínio do conteúdo de Física era crucial para que os alunos resolvessem os problemas propostos. Tal fato se refletiu nas entrevistas realizadas. Quando solicitados a resolverem um problema que envolvia a modelagem do movimento de um lustre que oscila, os dois entrevistados que apresentavam maior domínio do conteúdo envolvido no modelo de pêndulo simples propuseram soluções mais consistentes, assim como tiveram mais facilidade para apontarem as simplificações consideradas nesse modelo. Os outros dois entrevistados, que tinham menor domínio do conteúdo, apresentaram grandes dificuldades para modelarem o evento proposto.

Pôde-se verificar também que os estudantes apresentavam grandes dificuldades para modelarem os eventos que iriam investigar. A escolha de simplificações para esses eventos que tornassem os problemas menos complexos, por exemplo, era uma tarefa 
complicada para os estudantes. Foi evidente, no entanto, que essas dificuldades eram maiores para alunos que tinham menor domínio do conteúdo científico envolvido nos problemas.

\section{Considerações finais}

Neste estudo, fizemos uma primeira avaliação de uma proposta para dar novo significado às atividades experimentais, focando-as no processo de modelagem científica. Os resultados evidenciam que, apesar dos alunos não terem atingido todos os objetivos de aprendizagem que esperávamos no início do estudo, as atividades conduzidas têm potencial para defrontar os estudantes com problemas cuja solução requer algumas competências associadas com o processo de modelagem científica. Além disso, o fato de 10 dos 12 estudantes que terminaram a disciplina afirmarem ter preferência por ciclos de modelagem em comparação com as atividades tradicionais é um aspecto que não pode ser desprezado e que evidencia que a metodologia de ensino empregada tem potencial também para tornar as atitudes dos estudantes mais positivas frente às aulas experimentais. Dos resultados relacionados com as duas primeiras questões de pesquisa deste estudo, podemos levantar duas proposições teóricas, a serem avaliadas em estudos explanatórios futuros. São elas:

As atividades experimentais com enfoque no processo de modelagem científica conduzidas são frutíferas para:

- defrontar os estudantes com problemas abertos, dando liberdade para que eles realizem autênticas investigações, instando-os a dirigir esforços para saciar suas curiosidades e superar suas dificuldades conceituais durante as aulas.

- estimular o pensamento científico, a criatividade e a intuição física por parte dos estudantes.

Apesar dos aspectos positivos apresentados, podemos destacar dois resultados insatisfatórios:

- Os estudantes apresentaram significativa dificuldade para delinear as investigações que iriam realizar nos ciclos de modelagem. Algumas possíveis causas são: i) em atividades experimentais anteriormente realizadas costumavam seguir acriticamente uma série rígida de passos; ii) não compreendiam suficientemente os modelos teóricos necessários para interpretar os dados experimentais, e/ou iii) não tinham noções mínimas sobre o processo de modelagem científica. 
- As concepções dos estudantes sobre a natureza dos modelos e da modelagem científica permaneceram confusas após a disciplina. Refutando nossa hipótese inicial, em que julgávamos que as atividades desenvolvidas naturalmente levariam os alunos a compreender de forma satisfatória o processo de construção do conhecimento científico, esse resultado evidencia que o envolvimento dos alunos com problemas que abranjam o processo de modelagem científica não é suficiente para propiciar uma evolução nas suas concepções de Ciência. O tratamento explícito de aspectos relacionados com metamodelagem é imprescindível para que os estudantes amadureçam suas concepções sobre a natureza dos modelos e da modelagem científica, o que corrobora resultados já expostos na literatura (e.g., LEDERMAN, 2006; PRINS et al., 2011).

Refletindo sobre esses dois problemas, nos deparamos com perguntas importantes: Que conhecimentos desejamos que nossos estudantes apreendam para que sejam competentes para modelar eventos reais? Que atividades têm potencial para possibilitar que os estudantes desenvolvam esses conhecimentos? Que concepções sobre a natureza da Ciência desejamos que os estudantes compreendam? Que atividades têm potencial para possibilitar que os estudantes compreendam essas concepções?

Para responder a essas questões, é necessário o amparo em um referencial teórico que forneça subsídios para o estabelecimento dos conhecimentos que desejamos que os estudantes assimilem com as atividades desenvolvidas. Esses conhecimentos abrangem tanto o que se refere às competências necessárias para que enfrentem situações que demandem a construção, o uso e a validação de modelos científicos como o que tange à concepção sobre o processo de modelagem científica que se deseja que eles compreendam durante as aulas. Nesse contexto, a Modelagem Didático-Científica, de Brandão et al. (2011), se mostra uma alternativa de referencial teórico que tem potencial para amparar futuras investigações no que se refere ao estabelecimento dos conhecimentos que desejamos que os estudantes desenvolvam durante atividades de modelagem. Um novo estudo, amparado nessa teoria, já foi iniciado com o objetivo de procurar respostas para as questões levantadas neste estudo exploratório.

\section{Referências}

ABD-EL-KHALICK, F. Nature of science in science education: Toward a coherent framework for synergistic research and development. In: FRASER, B.; TOBIN, K. G.; MCROBBIE, C. J. (Eds.). Second International Handbook of Science Education, Dordrecht: Springer, 2012, p. 1041-1060. 
ABRAHAMS, I.; SAGLAM, M. A study of teachers' views on practical work in secondary schools in England and Wales. International Journal of Science Education, v. 32, n. 6, p. 753-768, 2010.

BRANDÃO, R. V.; ARAUJO, I. S.; VEIT, E. A. A modelagem científica vista como um campo conceitual. Caderno Brasileiro de Ensino de Física, v. 28, n. 3, p. 507-545, 2011.

BRANDÃO, R. V.; ARAUJO, I. S.; VEIT, E. A. ; SILVEIRA, F. L. Validación de un cuestionario para investigar concepciones de profesores sobre ciencia y modelado científico en el contexto de la Física. Revista Electrónica de Investigación en Educación en Ciencias, v. 6, n. 1, p. 43-60, 2011.

BREWE, E. Modeling theory applied: Modeling Instruction in introductory physics. American Journal of Physics, v.76, n.12, p. 1155-1160, 2008.

BUNGE, M. Teoria e realidade. São Paulo: Editora Perspectiva, 1974.

BUNGE, M. Caçando a realidade. São Paulo: Editora Perspectiva, 2010.

CUPANI, A.; PIETROCOLA, M. A relevância da epistemologia de Mario Bunge para o ensino de ciências. Caderno Brasileiro de Ensino de Física, v. 19, n. esp., p. 100-125, 2002.

DAY, C. Why I didn't become an experimental physicist. The Dayside, 8 May 2015. Disponível em: http://scitation.aip.org/content/aip/magazine/physicstoday/news/thedayside/why-i-didn-t-become-an-experimental-physicist-a-dayside-post. Acesso em: 07 jun. 2015.

DEACON, C.; HAJEK, A. Student perceptions of the value of physics laboratories. International Journal of Science Education, v. 33, n. 7, p. 943-977, 2011.

FIELD, A. Discovering statistics using SPSS (and sex and drugs and rock ' $n$ ' roll). Dubai: SAGE Publications, 2009.

HEIDEMANN, L. A. Ressignificação da atividades experimentais no ensino de Física por meio do enfoque no processo de modelagem científica. 2015. $298 \mathrm{f}$. Tese (Doutorado em Ensino de Física) - Instituto de Física, Universidade Federal do Rio Grande do Sul, Porto Alegre.

HEIDEMANN, L. A.; ARAUJO, I. S.; VEIT, E. A. Um referencial teóricometodológico para o desenvolvimento de pesquisas sobre atitude: a Teoria do Comportamento Planejado de Icek Ajzen. Revista Electrónica de Investigación en Educación en Ciencias, v. 7, n. 1, p. 1-10, 2012a.

HEIDEMANN, L. A.; ARAUJO, I. S.; VEIT, E. A. Ciclos de Modelagem: uma alternativa para integrar atividades baseadas em simulações computacionais e atividades experimentais no ensino de Física. Caderno Brasileiro de Ensino de Física, v. 29, n. Especial 2, p. 965-1007, 2012b. 
HEIDEMANN, L. A.; ARAUJO, I. S.; VEIT, E. A. Um estudo exploratórios sobre atividades experimentais para graduandos de Física focadas no processo de modelagem científica. In: IX CONGRESO INTERNACIONAL SOBRE INVESTIGACIÓN EN DIDÁCTICA DE LAS CIENCIAS, 2013, Girona. Enseñanza de las Ciencias. Barcelona: 2013.

HESTENES, D. Notes for a Modeling Theory of Science, Cognition and Instruction. In: GIREP CONFERENCE: MODELLING IN PHYSICS AND PHYSICS EDUCATION, Amsterdam, Netherlands, 2006.

HODSON, D. Hacia un enfoque más crítico del trabajo de laboratorio. Enseñanza de las Ciencias, v.12, n.3, p. 299-313, 1994.

HOFSTEIN, A.; LUNETTA, V. N. The laboratory in science education: foundations for the twenty-first century. Science Education, v. 88, n.1, 28-54, 2004.

JACKSON, J.; DUKERICH, L.; HESTENES, D. Modeling Instruction: an effective model for Science Education. Science Educator, v.17, n.1, p. 10-17, 2008.

LEDERMAN, N. G. Nature of Science: Past, present, and future. In: ABELL, S. K.; LEDERMAN, N. G. (Eds.). Handbook of research on science education. New York: Routledge, 2006, p. 831-879.

LOUCA, L; ZACHARIA, Z. Modeling-based learning in Science education: cognitive, metacognitive, social, material and epistemological contributions. Educational Review, Philadelphia, v. 64, n. 4, p. 471-492, 2012.

PIETROCOLA, M. Construção e realidade: o realismo científico de Mario Bunge e o ensino de ciências através de modelos. Investigações em Ensino de Ciências, v. 4, n. 3, p. 213-227, 1999.

PRINS, G. T.; BULTE, A. M. W.; PILOT, A. evaluation of a design principle for fostering students' epistemological views on models and modelling using authentic practices as contexts for learning in chemistry education. International Journal of Science Education, v. 33, n. 11, p. 1539-1569, 2011.

TRUMPER, R. The physics laboratory - A historical overview and future perspectives. Science \& Education, v. 12, n. 7, p. 645-670, 2003.

YIN, R. K. Estudo de caso: planejamento e métodos. $3^{\mathrm{a}}$ ed. Porto Alegre: Bookman, 2005.

YIN, R. K. Qualitative research from start to finish. New York: The Guilford Press, 2011.

WESTPHAL, M.; PINHEIRO, T. C. A epistemologia de Mario Bunge e sua contribuição para o ensino de ciências. Ciência \& Educação, v. 10, n. 3, p. 585-596, 2004. 
LEONARDO ALBUQUERQUE HEIDEMANN. Licenciado em Física (2008), mestre (2011) e doutor (2015) em Ensino de Física pela Universidade Federal do Rio Grande do Sul.

IVES SOLANO ARAUJO. Licenciado e bacharel em Física pela Universidade Federal de Rio Grande (2000). Mestre (2002) e doutor (2005) em Física, na área de concentração Ensino de Física, pela Universidade Federal do Rio Grande do Sul (UFRGS). Realizou estágio pós-doutoral na Universidade de Harvard (EUA, 20092010). Professor Associado do Departamento de Física da UFRGS e editor da revista Investigações em Ensino de Ciências (IENCI). Membro do Programa de Pós-Graduação em Ensino de Física da UFRGS atuando como professor e orientador de teses de doutorado e dissertações de mestrado (acadêmico e profissional). Bolsista de produtividade em pesquisa do $\mathrm{CNPq}$ - Nível 2 (Educação).

ELIANE ANGELA VEIT. Licenciada em Física (1975), mestre em Física (1979) e doutora em Ciências (1981) pela Universidade Federal do Rio Grande do Sul (UFRGS). Realizou estágio pós-doutoral na Universidade de British Columbia (Canadá, 19821984). Professora Titular do Departamento de Física da UFRGS e editora adjunta da revista Investigações em Ensino de Ciências (IENCI). Membro do Programa de PósGraduação em Ensino de Física da UFRGS atuando como professora e orientadora de teses de doutorado e dissertações de mestrado (acadêmico e profissional).

Recebido: 21 de junho de 2015

Revisado: 05 de outubro de 2015

Aceito: 27 de novembro de 2015 